\title{
Nifedipine and indomethacin in preventing preterm labor under 32 gestational weeks
}

\author{
(1) Gülşah Dağdeviren, (1) Münevver Aksoy, (1) Özge Yücel Çelik, (1) Ayşe Keleş, (1) Şevki Çelen, \\ (1) Ali Turhan Çağlar
}

University of Health Sciences Turkey, Etlik Zubeyde Hanim Obstetrics and Gynecology Training and Research Hospital, Clinic of Perinatology, Ankara, Turkey

Date submitted:

19.07.2021

Date accepted:

25.11.2021

Online publication date:

15.03.2022

\section{Corresponding Author:}

Gülşah Dağdeviren, M.D., University

of Health Sciences Turkey, Etlik

Zubeyde Hanim Obstetrics and

Gynecology Training and Research

Hospital, Clinic of Perinatology,

Ankara, Turkey

dagdevirengulsah@hotmail.com

ORCID:

orcid.org/0000-0003-3426-033X

Keywords: Indomethacin, nifedipine, preterm labor, tocolytic agents

\begin{abstract}
Aims: This study compared nifedipine and indomethacin treatments, commonly used tocolytic agents, in terms of efficacy and maternal side effects.
\end{abstract}

Methods: This retrospective study included pregnant women spontaneous preterm labor between 24 and 32 weeks of gestation who were treated with indomethacin or nifedipine between January 2017 and June 2020. Subjects with polyhydramnios, multiple pregnancies, preterm premature rupture of membranes, and those with $4 \mathrm{~cm}$ or more cervical dilatation, and who required emergency cesarean delivery were excluded. Study endpoints were delivery within $48 \mathrm{~h}$, prolongation of pregnancy up to 34 weeks and 37 weeks, and maternal side effects.

Results: A total of 307 pregnant women were analyzed. Nifedipine and indomethacin were administered to 205 and 102 patients, respectively. The median maternal age was 25 years in both groups. The rate of delivery within $48 \mathrm{~h}$ was significantly higher by $20.6 \%$ among subjects who received indomethacin compared with the $9.8 \%$ delivery rate among subjects who received nifedipine $(p=0.009)$. However, delivery after gestational 34 weeks and 37 weeks were significantly higher in the nifedipine group ( $p<0.001$ and $p=0.003$, respectively). No patients in the indomethacin group had side effects, but $6.8 \%$ of the nifedipine group required drug change due to side effects.

Conclusions: This study showed that nifedipine was superior to indomethacin in achieving a 48-hour delay in preterm labor, increasing the gestational age at birth, and decreasing the preterm delivery rates.

\section{Introduction}

Birth with a gestational age between 20 0/7 and 36 6/7 is called preterm (1). The prevalence of preterm birth is between $5 \%$ and $18 \%$ worldwide (2), and $15 \%$ occurs before the 32 nd week of gestation (3). Spontaneous preterm deliveries are responsible for $70-80 \%$ of all preterm deliveries (4). About $30 \%$ of women with acute preterm labor recover without treatment (5), and only $50 \%$ of the patients hospitalized for preterm labor experience preterm delivery (6-8).

Tocolytics are used to reduce or stop uterine contractions and delay or prevent labor by preventing the cervical change process. With tocolytic therapy, delivery is delayed for a short time $(48 \mathrm{~h})$ to allow sufficient time for administrating antenatal corticosteroids and neuroprotective magnesium sulfate.

Magnesium sulfate, beta-agonists, non-steroidal antiinflammatory drugs (NSAIDs), or calcium channel blockers (CCBs) are short-term tocolytic agents used to prevent preterm labor. NSAIDs and CCBs are the most effective agents in delaying labor and improving neonatal and maternal outcomes (9). The use of NSAIDs has been associated with premature closure of the ductus arteriosus and oligohydramnios (10). The use CCBs or NSAIDs between viability and 32 weeks or use CCBs at and after 32 weeks of gestation to stop preterm labor is recommended as a preventive measure (11). Hence, nifedipine from the CCB class and indomethacin from the NSAIDs class 
are widely used. Studies comparing NSAIDs and CCB have obtained different results (12-15).

This study aimed to compare the efficacy and maternal side effects of commonly used tocolytic nifedipine and indomethacin as the first-line treatment.

\section{Methods}

The study was conducted retrospectively between January 2017 and June 2020 and approved by the Etlik Zubeyde Hanim Obstetrics and Gynecology Training and Research Hospital Institutional Review Board (decision no: 2020-14/08, date: 14.09.2020).

The study included pregnant women at a gestational age between 24 and 32 weeks (confirmed by the date of last menstruation and first-trimester ultrasound) who were admitted to the hospital with spontaneous preterm labor, and were treated with nifedipine or indomethacin. Patients with polyhydramnios, multiple pregnancies, preterm premature rupture of membranes, or $4 \mathrm{~cm}$ or more cervical dilatation were excluded.

Preterm labor diagnosis was defined in line with the recommendations of the American College of Obstetricians and Gynecologists (ACOG) Committee on Practice Bulletins: Management of Preterm Labor: as "regular uterine contractions accompanied by changes in cervical dilatation and/or effacement or in the presence of signs of cervical dilatation of at least $2 \mathrm{~cm}$ in addition to regular contractions" (1).

In our center, nifedipine is administered orally at $10 \mathrm{mg} \mathrm{(1}$ capsule) in 3 doses, $20 \mathrm{~min}$ apart, followed by $10 \mathrm{mg}$ orally every $6 \mathrm{~h}$ for $48 \mathrm{~h}$. Indomethacin is given rectal $100 \mathrm{mg} \mathrm{(1}$ suppository) loading followed by $25 \mathrm{mg}$ orally every $6 \mathrm{~h}$ for $48 \mathrm{~h}$. A course of betamethasone (12 mg intramuscular 2 doses every $24 \mathrm{~h}$ ) to accelerate fetal lung maturation and neuroprotective magnesium sulfate $6 \mathrm{~g}$ loading and $2 \mathrm{~g} / \mathrm{h}$ maintenance therapy is given to women at high risk of delivery within $24 \mathrm{~h}$. Maternal blood pressure is monitored every 15 min for the first $2 \mathrm{~h}$, and every 4-6 hours thereafter. Medication changes due to maternal symptoms such as nausea, reflux, vomiting, flushing, headache, dizziness, palpitations, tachycardia, or maternal hypotension (systolic and diastolic blood pressure $<90 \mathrm{mmHg}$ and $<50$ $\mathrm{mmHg}$, respectively) are recorded. Uterine contractions are constantly monitored.

Information such as uterine contractions, maternal side effects, and time of delivery after treatment was obtained from the patient records. Response to treatment was defined as cessation of uterine contractions within the first $2 \mathrm{~h}$. Posttreatment birth information was recorded at three-time points (up to $48 \mathrm{~h}, 34$ weeks, or 37 weeks). Subjects whose drugs were changed due to side effects or drug unresponsiveness, those who needed an emergency cesarean section for any reason during treatment, and those who did not give birth in our hospital were further excluded from the study.

\section{Statistical Analysis}

Data were analyzed using Statistical Package for the Social Sciences Statistics for Windows, version 23.0 (Armonk, NY: IBM Corp., 2015). Kolmogorov-Smirnov test was used to test the distribution of the variables. Mann-Whitney $U$ test was used to compare the numerical data between the indomethacin and nifedipine groups if the variables were not normally distributed. The chi-square test was used to compare categorical variables between groups. Descriptive statistics were reported as median (interquartile range) for continuous variables and numbers (percentages) for categorical variables. $\mathrm{P}<0.05$ was considered statistically significant.

\section{Results}

A total of 330 patients hospitalized for preterm labor between 24 and 32 weeks of gestational age and who needed tocolysis were included in this analysis.

As shown in Table 1, age, body mass index, parity, previous preterm birth history, gestational age at the time of tocolysis, initial cervical dilatation and effacement status, and history of tocolysis in the current pregnancy was not different between the two groups.

Table 2 shows the obstetric results of the drug responses of both groups. In the first two hours, 84 patients $(82.4 \%)$ receiving indomethacin and 176 patients $(85.9 \%)$ receiving nifedipine responded to the tocolytic agent, and uterine contractions stopped ( $p=0.422$ ). Delivery occurred within $48 \mathrm{~h}$ in $20.6 \%$ and $9.8 \%$ of the patients receiving indomethacin and nifedipine, respectively $(p=0.009)$. Delivery occurred after 34 weeks of gestation in $47.1 \%$ of the patients treated with indomethacin and $67.8 \%$ of the patients treated with nifedipine $(p<0.001)$. Term delivery (>37 weeks) rates were $28.4 \%$ among the subjects treated with indomethacin and $45.9 \%$ among those who received nifedipine $(p=0.003)$. Preterm birth rates were $71.6 \%$ and $54.1 \%$ in the indomethacin and nifedipine groups, respectively $(p=0.004)$. The week of delivery was lower in those treated with indomethacin than those treated with nifedipine $(p<0.001)$.

Maternal side effects (hypotension $(n=8)$ and tachycardia $(n=7)$ requiring a drug change developed in $15(6.8 \%)$ of 220 patients using nifedipine. No patients receiving indomethacin was developed side effects. The rate of maternal side effects was significantly higher in the nifedipine group $(p=0.026)$. Eight $(7.3 \%)$ of 110 patients who received indomethacin were subject to drug change due to treatment unresponsiveness. These patients were excluded from the study due to medication changes. Of the remaining 307 patients, 205 were treated with nifedipine and 102 with indomethacin. Neuroprotective magnesium sulfate treatment was administered to 36 patients in the indomethacin and 19 patients in the nifedipine group, respectively. 


\begin{tabular}{|c|c|c|c|}
\hline & Indomethacin $(n=102)$ & Nifedipine ( $n=205)$ & $\mathbf{p}$ \\
\hline $\mathrm{Age}^{\mathrm{a}}$ & $25(8)$ & $25(7)$ & 0.541 \\
\hline Nullipare $^{b}$ & $62(60.8)$ & $125(61.0)$ & \multirow{2}{*}{0.974} \\
\hline Multipare $^{\mathrm{b}}$ & $40(39.2)$ & $80(39.0)$ & \\
\hline Gestational age $^{b}$ & $29(3.8)$ & $29(2.3)$ & 0.641 \\
\hline \multicolumn{4}{|l|}{ Prior tocolytic history ${ }^{b}$} \\
\hline Yes & $11(10.8)$ & $24(11.7)$ & 0.811 \\
\hline No & $91(89.2)$ & $181(88.3)$ & \\
\hline \multicolumn{4}{|l|}{ Cervical dilatation $^{b}$} \\
\hline$>50 \%$ & $27(26.5)$ & $39(19.0)$ & \\
\hline
\end{tabular}

Table 2. Obstetric outcomes $(n=307)$

\begin{tabular}{|c|c|c|c|}
\hline & $\begin{array}{l}\text { Indomethacin group } \\
(n=102)\end{array}$ & Nifedipine group ( $n=205$ ) & $p$ value \\
\hline Response in the first 2 hours $^{a}$ & $84(82.4)$ & $176(85.9)$ & 0.422 \\
\hline \multicolumn{4}{|l|}{ Gestational age at delivery ${ }^{a}$} \\
\hline$\geq 34$ week & $48(47.1)$ & $139(67.8)$ & $<0.001$ \\
\hline$\geq 37$ week & $29(28.4)$ & $94(45.9)$ & 0.003 \\
\hline Birth week ${ }^{b}$ & $33(7.5)$ & $36(5.6)$ & $<0.001$ \\
\hline
\end{tabular}

\section{Discussion}

The response to the drug in the first $2 \mathrm{~h}$ was similar in both groups. Delayed labor for $48 \mathrm{~h}$ and delivery after 34 weeks of gestation and after 37 weeks were significantly higher in the pregnant women taking nifedipine. Gestational age at birth was significantly lower in the women given indomethacin. Whereas no patient in the indomethacin group produced any side effects, $6.81 \%$ of them in the nifedipine group required drug change due to the side effects.

NSAID, CCB, betamimetics, magnesium sulfate, and oxytocin receptor antagonists used as tocolytic agents are more effective than placebo in delaying labor for $48 \mathrm{~h}(9,16)$. However, the use of betamimetics and magnesium sulfate is no longer recommended for tocolysis due to high maternal and fetal side effects $(11,17)$. Nifedipine and indomethacin are now more popular and widely used tocolytic agents. However, the choice of primary care treatment varies. The National Institute for Health and Care Excellence guideline (18), the French College of Gynecologists and Obstetricians guideline (19), and the World Health Organization (20) recommend nifedipine as a first-line treatment. Some authors recommend indomethacin as first-line tocolytic therapy for women between 24 and 32 weeks of gestation (12). In many studies, indomethacin treatment for tocolysis was compared with placebo with the result that indomethacin-prolonged pregnancy, but different results were shown in neonatal morbidity or mortality (14). A study by Haas et al. (21) concluded that indomethacin was effective in prolonging labor for $48 \mathrm{~h}$ compared to placebo, having low maternal side effects and good neonatal outcomes. A review article published in 2015 concluded that indomethacin was not different from placebo, magnesium sulfate, or CCB in terms of side effects, and it was associated with fewer maternal side effects than betamimetics (14). Kashanian et al. (13) reported that, among 79 preterm women, nifedipine was more successful than indomethacin in stopping contractions within $2 \mathrm{~h}$ of starting treatment. Additionally, when the contractions stopped within the first $2 \mathrm{~h}$ with indomethacin, the effect continued for up to $48 \mathrm{~h}$. Different from previous studies, although the response to treatment was similar in the first $2 \mathrm{~h}$, nifedipine was more effective than indomethacin in delaying delivery. 
A recent Cochrane review concluded that indomethacin was a powerful tocolytic with low maternal side effects but remained suspicious for fetal complications (17). NSAIDs cross the placental barrier and inhibit fetal prostaglandin synthesis; thus, due to decreased renal blood flow and increased vasopressin effect, fetal kidney failure and oligohydramnios develop in $70 \%$ of the cases with their use beyond 72 hours (22). Additionally, indomethacin is recommended before the $32 \mathrm{nd}$ week of gestation and for a maximum of $48 \mathrm{~h}$ to prevent premature closure of the ductus arteriosus (23). Although the ACOG recommends indomethacin for treating preterm labor (1), indomethacin treatment is not recommended by some authors and organizations $(14,20,24,25)$, or limited use is recommended due to controversial and insufficient data (26). Our study did not evaluate the effects of nifedipine and indomethacin on the fetus; on the other hand, it focused on the effectiveness of nifedipine and indomethacin in stopping preterm labor.

CCB causes relaxation of the myometrium by blocking the flow of calcium through the cell membranes. The commonly used agent in this group is nifedipine (11). Haas et al. (21) reported that CCBs could delay the delivery for $48 \mathrm{~h}$ in $66 \%$ of the preterm labor cases and seven days in $62 \%$ of them. In a review comparing tocolytic agents, the authors reported that nifedipine was superior to betamimetics in delaying delivery beyond 48 h, seven days, and 34 weeks of gestation (27). Additionally, nifedipine reduces adverse neonatal outcomes relative to betamimetics and NSAIDs. In a single-center, randomized clinical trial that compared magnesium sulfate, nifedipine, and indomethacin for efficacy and maternal side effects among women with acute preterm labor, no differences among the three drugs were observed in delaying delivery for more than 48 $\mathrm{h}$ or seven days. Additionally, there was no difference in terms of gestational age at birth (28). CCBs improved neonatal morbidity compared to NSAIDs (11). Nifedipine is one of the safe tocolytic agents first preferred in clinical practice in medical treatment in the threat of preterm labor due to its rarity of maternal and fetal side effects and its oral applicability (29). In our study, only $9.8 \%$ of the patients who received nifedipine delivered before $48 \mathrm{~h}$. Unlike previous studies, nifedipine was more successful in delaying labor than indomethacin, and the gestational age at birth was longer. We suggest that the pregnancy with preterm labor, the first choice of drug should be nifedipine to prevent birth before 32 weeks of gestation, and indomethacin should be an option for those who cannot tolerate nifedipine.

Our study has some limitations. We did not record the newborn outcomes. Additionally, we could not evaluate the effects of combinations as the number of patients who received nifedipine plus magnesium sulfate therapy was small. However, the study includes a reliable analysis of the response to tocolytic therapy and maternal side effects among patients presenting with preterm labor.

\section{Conclusion}

In conclusion, the results of our study showed nifedipine was superior to indomethacin in delaying labor for $48 \mathrm{~h}$, which is the goal of treatment in preterm labor. Thus, increasing the gestational age at birth and reducing preterm birth rates were more likely with nifedipine.

\section{Ethics}

Ethics Committee Approval: The study was approved by the Etlik Zubeyde Hanim Obstetrics and Gynecology Training and Research Hospital Institutional Review Board (decision no: 2020-14/08, date: 14.09.2020).

Informed Consent: Retrospective study.

Peer-review: Externally peer-reviewed.

\section{Authorship Contributions}

Surgical and Medical Practices: G.D., Concept: G.D., Design: G.D., Data Collection or Processing: M.A., Analysis or Interpretation: Ö.Y.Ç., A.K., Literature Search: G.D., Ş.Ç., A.T.Ç., Writing: G.D., A.T.Ç.

Conflict of Interest: No conflict of interest was declared by the authors.

Financial Disclosure: The authors declared that this study received no financial support.

\section{References}

1. American College of Obstetricians and Gynecologists' Committee on Practice Bulletins--Obstetrics. Practice Bulletin No. 171: Management of Preterm Labor. Obstet Gynecol. 2016;128:155-164.

2. Blencowe $\mathrm{H}$, Cousens $\mathrm{S}$, Oestergaard $\mathrm{MZ}$, et al. National, regional, and worldwide estimates of preterm birth rates in the year 2010 with time trends since 1990 for selected countries: a systematic analysis and implications. Lancet. 2012;37:21622172.

3. World Health Organization WHO, March of Dimes, Partnership for Maternal, Newborn \& Child Health, Save the Children. Born too soon: the global action report on preterm birth. Last Accessed Date: February 15, 2021. Available from: www.who. int/maternal _ child_adolescent/documents/born_too_soon/ en/

4. Robinson JN, Norwitz ER. Preterm birth: risk factors, interventions for risk reduction, and maternal prognosis. Uptodate. https://www.uptodate.com/contents/preterm-birthrisk-factors-interventions-for-risk-reduction -and-maternalprognosis. Accessed March 1, 2021

5. Lewit EM, Baker LS, Corman H, Shiono PH. The direct cost of low birth weight. Future Child. 1995;5:35-56.

6. Ferguson JE, Dyson DC, Holbrook RH Jr, Schutz T, Stevenson DK. Cardiovascular and metabolic effects associated with nifedipine and ritodrine tocolysis. Am J Obstet Gynecol. 1989;161:788-795.

7. Ferguson JE, Dyson DC, Schutz T, Stevenson DK. A comparison of tocolysis with nifedipine or ritodrine: analysis 
of efficacy and maternal, fetal, and neonatal outcome. Am J Obstet Gynecol. 1990;163:105-111.

8. Bracero LA, Leikin E, Kirshenbaum N, Tejani N. Comparison of nifedipine and ritodrine for the treatment of preterm labor. Am J Perinatol. 1991;8:365-369.

9. Haas DM, Caldwell DM, Kirkpatrick P, Mclntosh JJ, Welton NJ. Tocolytic therapy for preterm delivery: systematic review and network meta-analysis. BMJ. 2012;345:e6226.

10. Coomarasamy A, Knox EM, Gee H, Song F, Khan KS. Effectiveness of nifedipine versus atosiban for tocolysis in preterm labour: a meta-analysis with an indirect comparison of randomised trials. Br J Obstet Gynecol. 2003;110:1045-1049.

11. Hanley M, Sayres L, Reiff ES, Wood A, Grotegut CA, Kuller JA. Tocolysis: A Review of the Literature. Obstet Gynecol Surv. 2019;74:50-55.

12. Simhan HN, Caritis S. Inhibition of acute preterm labor. UpToDate. [cited 2021 March 1] Available from: https://www. uptodate.com/contents/inhibition-of-acute-preterm-labor

13. Kashanian M, Bahasadri S, Zolali B. Comparison of the efficacy and adverse effects of nifedipine and indomethacin for the treatment of preterm labor. Int J Gynaecol Obstet. 2011;113:192-195.

14. Reinebrant HE, Pileggi-Castro C, Romero CL, et al. Cyclooxygenase (COX) inhibitors for treating preterm labour. Cochrane Database Syst Rev. 2015;2015:CD001992.

15. Klauser CK, Briery CM, Martin RW, Langston L, Magann EF, Morrison JC. A comparison of three tocolytics for preterm labor: a randomized clinical trial. J Matern Fetal Neonatal Med. 2014;27:801-806.

16. Haas DM, Kirkpatrick P, McIntosh JJ, Caldwell DM. Assessing the quality of evidence for preterm labor tocolytic trials. J Matern Fetal Neonatal Med. 2012;25:1646-1652.

17. Rath W, KehI S. Acute Tocolysis - a Critical Analysis of EvidenceBased Data. Geburtshilfe Frauenheilkd. 2018;78:1245-1255.

18. National Collaborating Centre for Women's and Children's Health (UK). Preterm Labour and Birth. London: National Institute for Health and Care Excellence (UK); 2015 Nov. Last Accessed Date: February 10, 2021. Available from: https:// www.ncbi.nlm.nih.gov/books/NBK327571
19. Sentilhes L, Sénat MV, Ancel PY, et al. Prevention of spontaneous preterm birth: Guidelines for clinical practice from the French College of Gynaecologists and Obstetricians (CNGOF). Eur J Obstet Gynecol Reprod Biol. 2017;210:217224.

20. Vogel JP, Oladapo OT, Manu A, Gülmezoglu AM, Bahl R. New WHO recommendations to improve the outcomes of preterm birth. Lancet Glob Health. 2015;3:589-590.

21. Haas DM, Imperiale TF, Kirkpatrick PR, Klein RW, Zollinger TW, Golichowski AM. Tocolytic therapy: a meta-analysis and decision analysis. Obstet Gynecol. 2009;113:585-594.

22. Hendricks SK, Smith JR, Moore DE, BrownZA. Oligohydramnios associated with prostaglandin synthetase inhibitors in preterm labour. Br J Obstet Gynaecol. 1990;97:312-318.

23. Reinebrant HE, Pileggi-Castro C, Romero CL, et al. Cyclooxygenase (COX) inhibitors for treating preterm labour. Cochrane Database Syst Rev. 2005;2015:CD001992.

24. Hammers AL, Sanchez-Romero L, Kaunitz AM. Antenatal exposure to indomethacin increased the risk of severe intraventricular haemorrhage, necrotizing enterocolitis, and periventricular leukomalacia: a systematic review with metaanalysis. Am J Obstet Gynecol. 2015;212:505.

25. Nijman TA, van Vliet EO, Koullali B, Mol BW, Oudijk MA. Antepartum and intrapartum interventions to prevent preterm birth and its sequelae. Semin Fetal Neonatal Med. 2016;21:121-128.

26. Navathe R, Berghella V. Tocolysis for acute preterm labour: Where have we been, where are we now, and where are we going? Am J Perinatol. 2016;33:229-235.

27. Conde-Agudelo A, Romero R, Kusanovic JP. Nifedipine in the management of preterm labor: a systematic review and metaanalysis. Am J Obstet Gynecol. 2011;204:134.

28. Lima MM, Souza AS, Diniz C, Porto AM, Amorim MM, Moron AF. Doppler velocimetry of the uterine, umbilical and fetal cerebral arteries in pregnant women undergoing tocolysis with oral nifedipine. Ultrasound Obstet Gynecol. 2009;34:311-315.

29. Erol SA, Kırbaş A, Engin Üstün Y. The Role of Tocolytic Agents and Calcium Channel Blockers (Nifedipine) In Preterm Birth Management. The Journal of Gynecology - Obstetrics and Neonatology. 2020;17:621-628. 